\title{
STUDIES ON THE PIGMENTS OF MARINE ANIMALS -VII. CAROTENOIDS IN THE SKIN AND FINS OF SOME MARINE FISHES-
}

AUTHOR(S):

Nishibori, Kokichi

\section{CITATION:}

Nishibori, Kokichi. STUDIES ON THE PIGMENTS OF MARINE ANIMALS -VII. CAROTENOIDS IN THE SKIN AND FINS OF SOME MARINE FISHES-. PUBLICATIONS OF THE SETO MARINE BIOLOGICAL LABORATORY 1959, 7(3): 339-348

\section{ISSUE DATE:}

1959-12-20

URL:

http://hdl.handle.net/2433/174632

RIGHT: 


\section{STUDIES ON THE PIGMENTS OF MARINE ANIMALS \\ VII. CAROTENOIDS IN THE SKIN AND FINS \\ OF SOME MARINE FISHES}

KOKICHI NISHIBORI

Notre Dame Seishin College, Okayama

With Plate $X X X, 5$ Table and 5 Text-figures

The skin and fins of fishes show various colours which are mainly due to melanins and carotenoids. The carotenoids of the skin and fins of fish have been investigated by many workers and the results were summarized by Fox (1953), GoodwiN (1952) and KARRER (1950). They pointed out that xanthophyll, astaxanthin and taraxanthin are predominant but the isolation of the crystalline carotenoid has not been achieved in the majority of cases.

The present study concerns carotenoids in the skin and fins of four species of

Table 1. Species, numbers and colours of the marine fishes analysed.

\begin{tabular}{l|c|l}
\hline \multicolumn{1}{c|}{ Species } & No. of specimens for sample & Colour of skin and fine \\
\hline Parabembras curtus & 14 & Red \\
Lepidotrigla microptera & 10 & Orange-red \\
Sebastes inermis & 6 & Dirty brown-red \\
Taius tumifrons & 3 & Yellow-pink \\
\hline
\end{tabular}

Table 2. Absorption maxima of carotenoids in the skin and fins of four species of marine fish (in $\mathrm{CS}_{2}$ ).

\begin{tabular}{|c|c|c|c|c|c|}
\hline \multirow{2}{*}{ Species } & \multirow{2}{*}{$\begin{array}{l}\text { Free } \\
\text { xantho- } \\
\text { phyll }\end{array}$} & \multicolumn{2}{|c|}{ Esterified xanthophyll } & \multirow{2}{*}{\multicolumn{2}{|c|}{ Carotenoid hydrocarbon }} \\
\hline & & Astacene & Yellow xanthophyll & & \\
\hline Parabembras curtus & $* *$ & $\sim 510 \mathrm{~m} \mu$ & f(II) $438,466,498 \mathrm{~m} \mu$ & & **_ \\
\hline Lepidotrigla microptera & $* *$ _ & $\sim 510 \mathrm{~m} \mu$ & $\mathrm{f}(\mathrm{I}) \quad 438,465,497 \mathrm{~m} \mu$ & & $* *$ \\
\hline Sebastes inermis & $* *$ & $-510 \mathrm{~m} \mu$ & $\mathrm{f}(\mathrm{I}) \quad 438,467,500 \mathrm{~m} \mu$ & $\left\{\begin{array}{c}*_{\mathbf{f}}(\mathrm{I}) \\
\mathbf{f}(\mathrm{II})\end{array}\right.$ & $\begin{array}{l}440,468,500 \mathrm{~m} \mu \\
443,472,498 \mathrm{~m} \mu\end{array}$ \\
\hline Taius tumifrons & $* *$ & $\sim 510 \mathrm{~m} \mu$ & 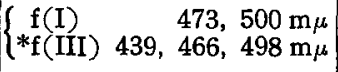 & $f(I)$ & $438,466,498 \mathrm{~m} \mu$ \\
\hline
\end{tabular}

Publ. Seto Mar. Biol. Lab., VII (3), 1959. (Article 24) 
marine fish having a red, brown-red and yellow-pink colour (Table 1). The results are summarized in Table 2.

The principal carotenoid of each species is found in the fraction of esterified xanthophyll, which is divided into two fractions; one of which is red and the other is yellow. The former seems to be esterified astaxanthin, as the crystalline red ketonic carotenoid which is recognized to be identical with astacene because of its properties (crystalline form, melting point, absorption maximum alone and when mixed with authentic astacene prepared from lobster) has been isolated. The latter is a yellow xanthophyll having absorption maxima at $438,466,498 \mathrm{~m} \mu$ (in $\mathrm{CS}_{2}$ ) which resembles sarcinaxanthin.

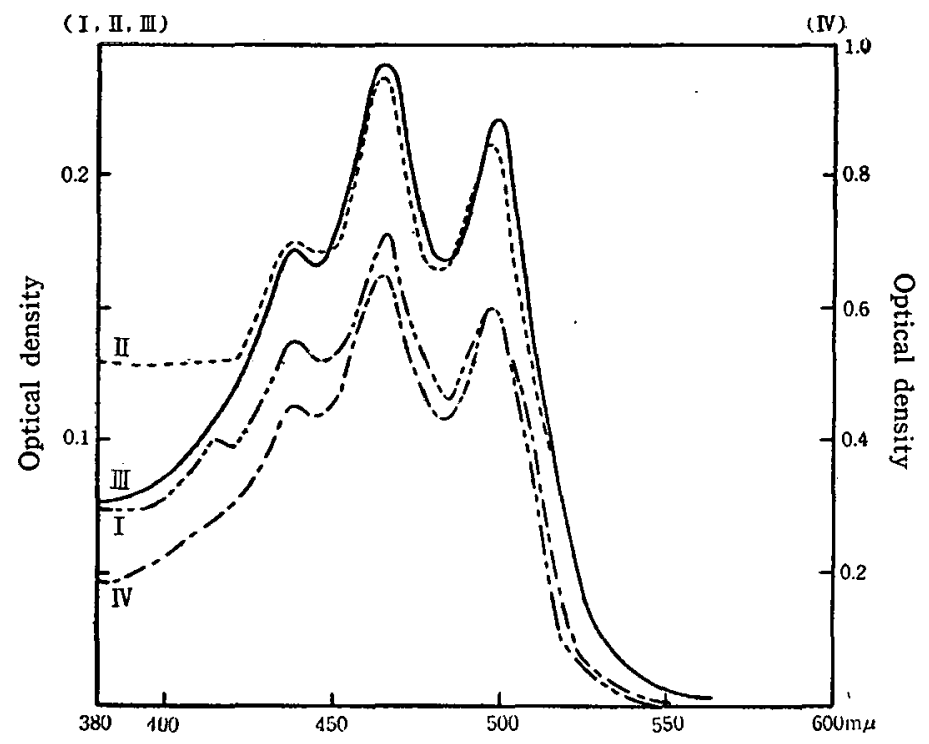

Fig. 1. Absorption spectra of the principal yellow xanthophyll separated from the skin and fins of four species of marine fish, in carbon disulphide.

I) Parabembras curtus. II) Lepidotrigla microptera.

III) Sebastes inermis. IV) Taius tumifrons.

Carotenoid

Yellow xanthophyll from the skin and fins of marine fish
Absorption maxima in $\mathrm{CS}_{2}$ $438,466,498 \mathrm{~m} \mu$ ....................436, 466.5, $499 \mathrm{~m} \mu$ ................................436, 441, 469, $501 \mathrm{~m} \mu$

Sarcinaxanthin

Taraxanthin

This yellow xanthophyll is contained in each of the four species and forms a main yellow pigment component (Fig. 1).

The colour of the skin and fins of fishes examined, is affected mainly by the 
concentration of astaxanthin and the yellow xanthophyll; in the case of Parabembras curtus having red skin and fins, the concentration of astaxanthin is much greater than that of the yellow xanthophyll, and in the case of Taius tumifrons having yellow-pink skin and fins, however, the concentration of astaxanthin and yellow xanthophyll is not so different. (see Tables 4,5 and Fig. 5)

\section{Material and method}

The specimens of the marine fishes used in this experiment are shown in Table 1. Extraction and separation of the carotenoid was carried out in the procedure shown in Table 3.

Table 3. Extraction and separation method

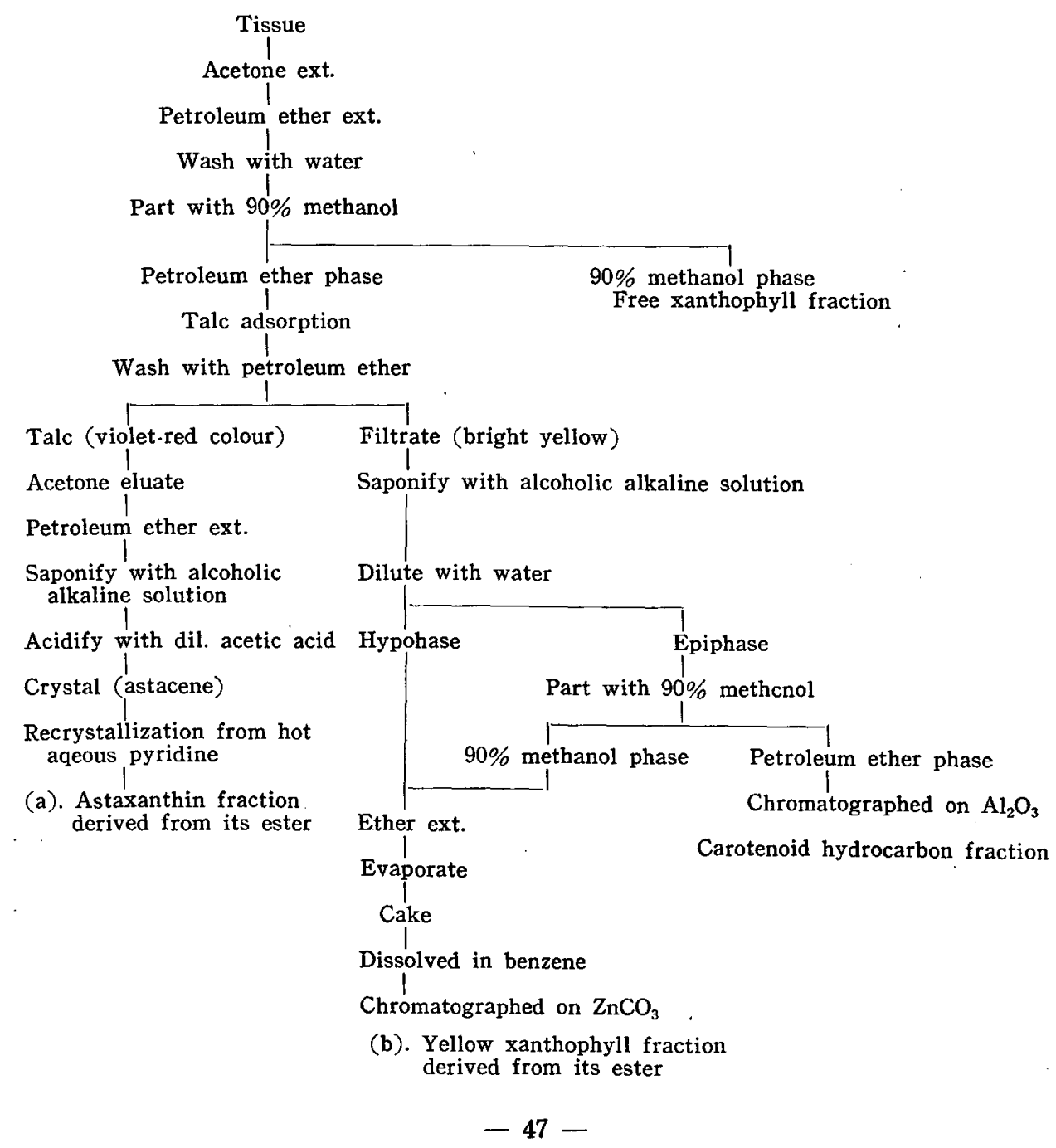




\section{Result}

The principal pigment was found in the fraction of esterified xanthophyll. Detailed results for each of marine fishes are given below.

I. Parabembras curtus (TEMminck et Schlegel) (Japanese name; Ubagochi).

An amount of $60 \mathrm{~g}$ of skin and fins from 14 freezing specimens obtained at a fish-market was used for acetone extraction. The freshness of the samples was not so good.

Free xanthophyll fraction: None of carotenoid was detected.

Esterified xanthophyll fraction: (a) Astaxanthin fraction. Crystalline carotenoid, violet-black needle, was isolated (Plate XXX, fig. 1). It melts at $214^{\circ} \mathrm{C}$ and showed

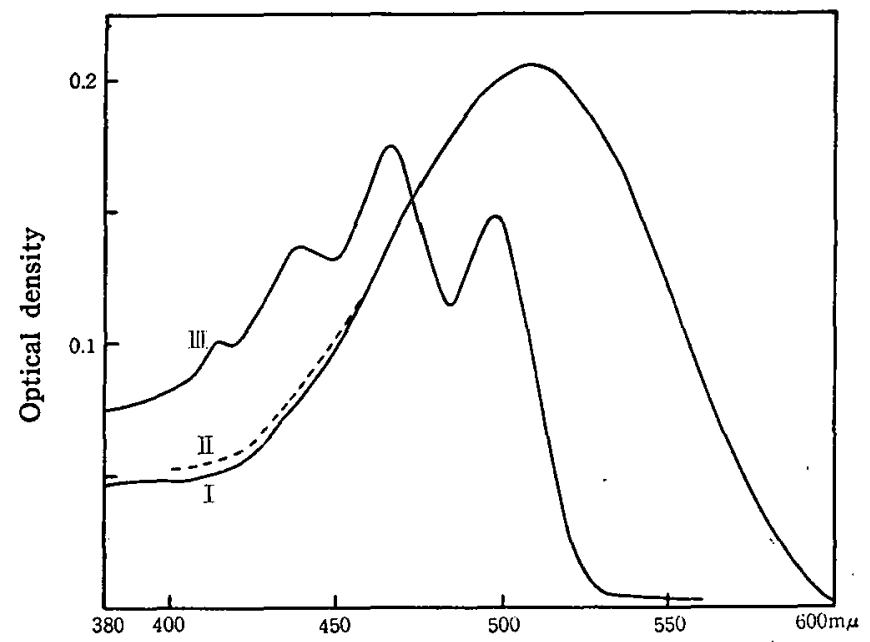

Fig. 2. Absorption spectra of carotenoids from the skin and fins of Parabembras curtus, in carbon disulphide.

I) Astacene from the esterified astaxanthin.

II) Mixed solution of I and lobster astacene.

III) Yellow xanthophyll zone (ii).

the absorption maximum at $\sim 510 \mathrm{~m} \mu$ in carbon disulphide (Fig. 2, I). CARR-PRICE reaction $(t)$ blue, conc. $\mathrm{H}_{2} \mathrm{SO}_{4}$ reaction $(t)$ blue. Mixed absorption maximum with astacene (isolated from a deep-water lobster, Linuparus trigonus von SIEBOLD, m. p. $217^{\circ} \mathrm{C}$, Plate XXX, fig. 2, absorption maximum $\sim 510 \mathrm{~m} \mu$ in $\mathrm{CS}_{2}$, Fig. 3, II) was at $\sim 510 \mathrm{~m} \mu$ in the same solvent. (Fig. 2, II). These properties indicate that the crystalline carotenoid is identical with astacene.

(b) Yellow xanthophyll fraction. Two zones were formed when it was chromatographed on the column of zinc carbonate from benzene solution and developed with petroleum ether containing acetone (10\%). 
Colour of zone

Absorption maxima in $\mathrm{CS}_{2}$

(i) Red-pink

(ii) Deep yellow (main zone) $413,438,466,498 \mathrm{~m} \mu$

The absorption spectrum of (ii) was shown in Fig. 2, III.

Carotenoid hydrocarbon fraction: The colour of this fraction was too minute to determine.

II. Lepidotrigla microptera (GüNTHER) (Japanese name; Kanagashira).

An amount of $70 \mathrm{~g}$ of skin and fins from 10 freezing specimens obtained at a fish-market was used.

Free xanthophyll fraction: The 90\% methanol solution of this fraction was almost entirely colourless.

Esterified xanthophyll fraction: (a) Astaxanthin fraction. Black-violet needles, m. p. $214^{\circ} \mathrm{C}$ (Plate XXX, fig. 3) were isolated. Absorption maximum was at $\sim 510 \mathrm{~m} \mu$ in carbon disulphide. Mixed absorption maximum with astacene was at $\sim 510 \mathrm{~m} \mu$ in carbon disulphide. CARR-PRICE reaction $(+)$ blue.

(b) Yellow xanthophyll fraction. Two zones were formed from the top of the column of zinc carbonate when it was developed with petroleum ether containing acetone (10\%).

Colour of zone

Absorption maxima in $\mathrm{CS}_{2}$

(i) Light pink

(ii) Yellow (main zone) $438,465,497 \mathrm{~m} \mu$

The absorption spectrum of (ii) was shown in Fig. 1, II.

Carotenoid hydrocarbon fraction: The amount of the carotenoid in this fraction was little.

III. Sebastes inermis (Cuvier et VAlEnciennes) (Japanese name; Mebaru).

An amount of $60 \mathrm{~g}$ of the fresh skin and fins from 6 specimens (about $15 \mathrm{~cm}$ in average length) collected at Okayama Prefecture was used for extraction.

Free xanthophyll fraction: The 90\% methanol solution containing the pigment of this fraction was almost colourless.

Esterified xanthophyll fraction: (a) Astaxanthin fraction. Black-violet sickleshaped needles, m. p. $221.5^{\circ} \mathrm{C}$, were isolated (Plate XXX, fig. 4). The yield was about $1 \mathrm{mg}$. Absorption maximum was at $\sim 510 \mathrm{~m} \mu$ in carbon disulphide (Fig. 3, I). It possessed a hypophasic property and was soluble in organic solvents (chloroform, carbon disulphide, pyridine and acetone) and sparingly soluble in petroleum ether. CARR-PRICE reaction $(+)$ violet, conc. $\mathrm{H}_{2} \mathrm{SO}_{4}$ reaction $(+)$ blue, mixed absorption maximum with astacene showed also at $\sim 510 \mathrm{~m} \mu$ in carbon disulphide (Fig. 3, III).

(b) Yellow xanthophyll fraction. The bulk of the yellow pigment was found in this fraction. Bright yellow benzene solution was chromatographed on the column of zinc carbonate and developed with petroleum ether containing acetone (10\%). 
Deep red zone (i), moving down slowly, was found. The absorption maxima of (i) showed at 438,467, $500 \mathrm{~m} \mu$ in carbon disulphide (Fig. 3, IV). Any attempt to isolate the crystalline carotenoid failed.

Carotenoid hydrocarbon fraction: This faction was poor in colour. The petroleum ether solution (light yellow) was chromatographed on the column of alumina (Merck) and developed with petroleum ether containing acetone (10\%).

Three zones were formed.

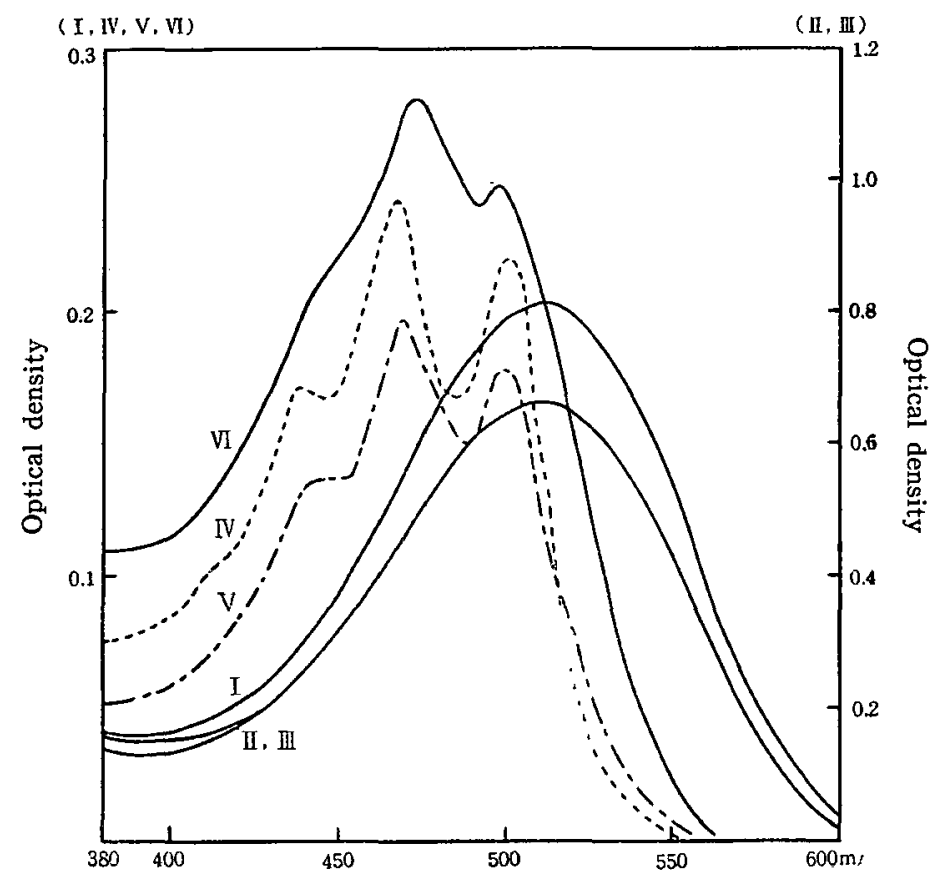

Fig. 3. Absorption spectra of carotenoids from the skin and fins of Sebastes inermis, in carbon disulphide.

I) Astacene from the esterified astaxanthin fraction.

II) Astacene from lobster.

III) Mixed solution of I and II.

IV) Yellow xanthophyll, zone (i).

V) Carotenoid hydrocarbon zone (i).

vI) Carotenoid hydrocarbon zone (ii).

Colour of zone

Absorption maxima in $\mathrm{CS}_{2}$

(i) Bright yellow (main zone). $\sim 440,468,500 \mathrm{~m} \mu$

(ii) Light orange $\sim 443,472,498 \mathrm{~m} \mu$

(iii) Extremely light yellow

The absorption spectra of (i) and (ii) were shown in Fig. 3, V and VI. 
IV. Taius tumifrons (TеMminck et Schlegel) (Japanese name; Kidai).

An amount of $60 \mathrm{~g}$ of skin and fins from 3 specimens $(20 \mathrm{~cm}$ in average length) collected at Okayama Prefecture were used.

Free xanthophyll fraction: Trace of colour was detected.

Esterified xanthophyll fraction: (a) Astaxanthin fraction. Crystalline carotenoid, m. p. $205^{\circ} \mathrm{C}$, black-violet sickle-shaped needle, was isolated (Plate XXX, fig. 5). The absorption maximum was at $\sim 510 \mathrm{~m} \mu$ in carbon disulphide (Fig. 4, I). It had hypophasic property. CARR-PRICE reaction $(t)$ blue, conc. $\mathrm{H}_{2} \mathrm{SO}_{4}$ reaction $(t)$ blue. There was no displacement of the absorption maximum mixed with the lobster astacene (Fig. 4, II).

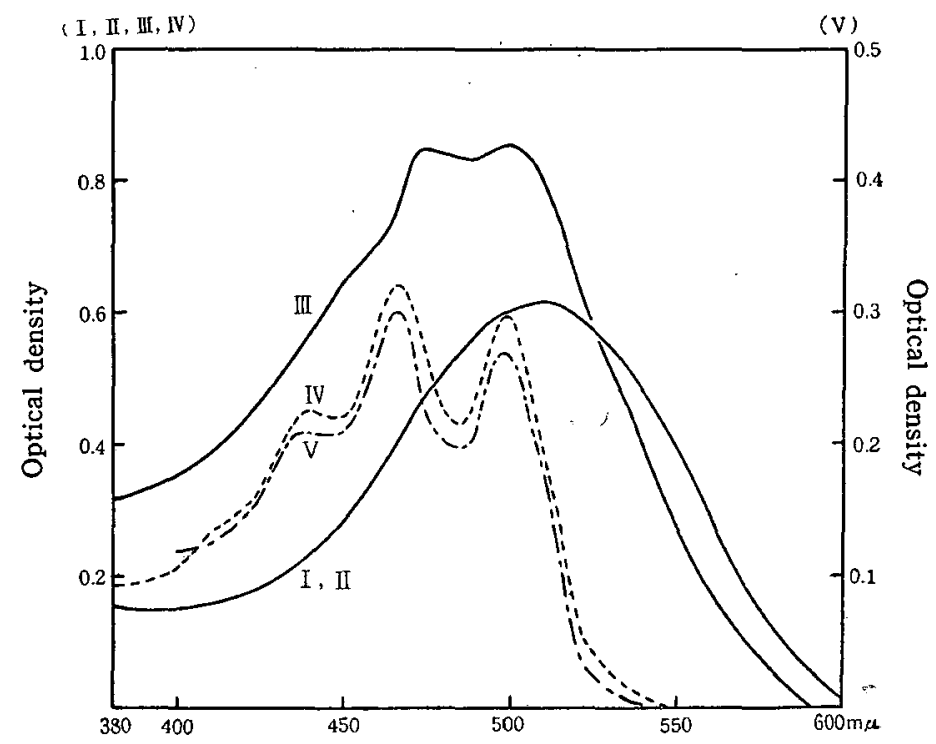

Fig. 4. Absorption spectra of carotenoids from the skin and fins of Taius tumifrons, in carbon disulphide.

I) Astacene from the esterified astaxanthin.

II) Maxed solution of I and lobster astacene.

III) Yellow xanthophyll zone (i).

IV) Yellow xanthophyll zone (iii).

v) Carotenoid hydrocarbon zone(i).

(b) Yellow xanthophyll fraction. The yellow colour of the specimens owed to this fraction. When the benzene solution of the pigment was chromatographed on the column of zinc carbonate and developed with petroleum ether containing acetone (10\%), three zones were obtained from the top of the column.
Colour of zone
Absorption maxima in $\mathrm{CS}_{2}$

(i) Bright red $473,500 \mathrm{~m} \mu$

(ii) Extremely light yellow $439,466,498 \mathrm{~m} \mu$

(iii) Orange (main zone) 
The absorption spectra of (i) and (iii) was shown in Fig. 4, III and IV.

Carotenoid hydrocarbon fraction: Two zones were found when the petroleum ether solution (light yellow) of this fraction was chromatographed on the column of alumina and developed with petroleum ether containing acetone (10\%).

Colour of zone

Absorption maxima in $\mathrm{CS}_{2}$

(i) Yellow (main zone) $438,466,498 \mathrm{~m} \mu$

(ii). Extremely light yellow

The absorption spectrum of (i) was shown in Fig. 4, V.

V. Determination of concentration of the red and yellow carotenoid.

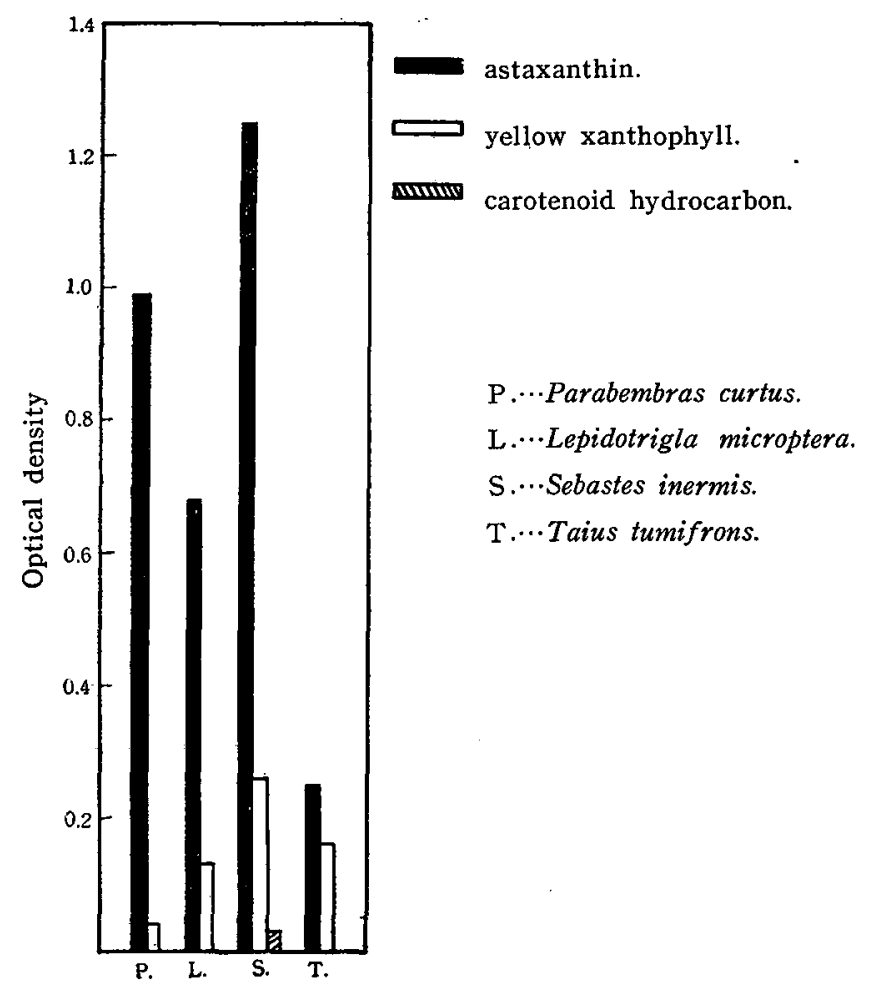

Fig. 5. Relative concentration of astaxanthin, yellow xanthophyll and carctenoid hydrocarbon in the skin and fins of four species of marine fish.

Carotenoid pigments in the $17 \mathrm{~g}$ of the skin and fins of each of four species of marine fish, were extracted entirely and separated into three fractions; astaxanthin (red colour), yellow xanthophyll (yellow colour) and carotenoid hydrocarbon (yellow colour). Each fraction was dissolved in $200 \mathrm{cc}$ of carbon disulphide respectivelly and determined their own optical density (AKA type electric colorimeter. Cell; $1 \mathrm{~cm}$, 
Filter; $\mathrm{S}_{50}$ for astaxanthin, $\mathrm{S}_{47}$ for yellow xanthophyll and carotenoid hydrocarbon). The results are summarized in Tables 4,5 and Fig. 5.

Table 4. The optical density of astaxanthin, yellow xanthophyll and carotenoid hydrocarbon fraction.

\begin{tabular}{l|c|c|c}
\hline \multirow{2}{*}{ Species } & \multicolumn{3}{|c}{ Optical density } \\
\cline { 2 - 4 } & Astaxanthin & Yellow xanthophyll & Carotenoid hydrocarbon \\
\hline Parabembras curtus & 0.995 & 0.040 & $-{ }^{*}$ \\
Lepidotrigla microptera & 0.680 & 0.135 & - N $^{*}$ \\
Sebastes inermis & 1.250 & 0.260 & 0.040 \\
Taius tumifrons & 0.255 & 0.170 & $-{ }^{*}$ \\
\hline
\end{tabular}

* Carotenoid content was too minute to determine.

Table 5. Relation between the colour of skin and fins, and the ratio of optical density of astaxanthin to yellow xanthophyll.

\begin{tabular}{l|l|l}
\hline \multicolumn{1}{c|}{ Species } & Colour of skin and fins & $\begin{array}{l}\text { Optical density of astaxanthin } \\
\text { Optical density of yellow } \\
\text { xanthophyll }\end{array}$ \\
\hline Parabembras curtus & Red & $24.9 / 1$ \\
Lepidotrigla microptera & Orange-red & $5.0 / 1$ \\
Sebastes inermis & Dirty brown-red & $4.8 / 1$ \\
Taius tumifrons & Yellow-pink & $1.5 / 1$ \\
\hline
\end{tabular}

\section{Summary}

The distribution of carotenoids in the skin and fins of four species of marine fish has been examined. The amount of free xanthophyll and carotenoid hydrocarbon was minute and the esterified xanthophyll was dominant. Esterified xanthophyll was divided into two fractions; a red xanthophyll which was recognized to be esterified astaxanthin and a yellow xanthophyll resembling sarcinaxanthin in the absorption maxima.

These two carotenoids were the principal pigment component of the skin and fins of each species. The relationship between the colour of the skin and fins of these fishes and the concentration of the two principal carotenoids was examined.

\section{Acknowledgment}

The author wishes to express his deep gratitude to Professor Y, Nakamura and Professor T. SAITO of Hokkaido University for their encouragement and guidance. The author is also grateful to Professor S. Mizuhara of Okayama University for permission to use autorecording Beckman electric spectrophotometer and to Dr. H. UTINOMI 
of Seto Marine Biological Laboratory of Kyoto University who gave the opportunity for publication.

\section{REFERENCES}

Fox, D. L. 1953. Animal biochromes and structural colours, Cambridge University Press. London. Goodwin, T. W. 1952. The comparative biochemistry of the carotenoids, Chapman \& Hall Ltd. London.

Karrer, P. and Jucker, E. 1950. Carotenoids, Elsevier Publishing Company, Inc., New York.

\section{EXPLANATION OF PLATE XXX}

Fig. 1. Astacene from the skin and fins of Parabembras curtus.

Fig. 2. Astacene isolated from a crustacean decapod Linuparus trigonus von Siebold.

Fig. 3. Astacene from the skin and fins of Lepidotrigla microptera.

Fig. 4. Astacene from the skin and fins of Sebastes inermis.

Fig. 5. Astacene from the skin and fins of Taius tumifrons. 
Publ. Seto Mar. Biol. Lab., VII, 3 (1959)

1

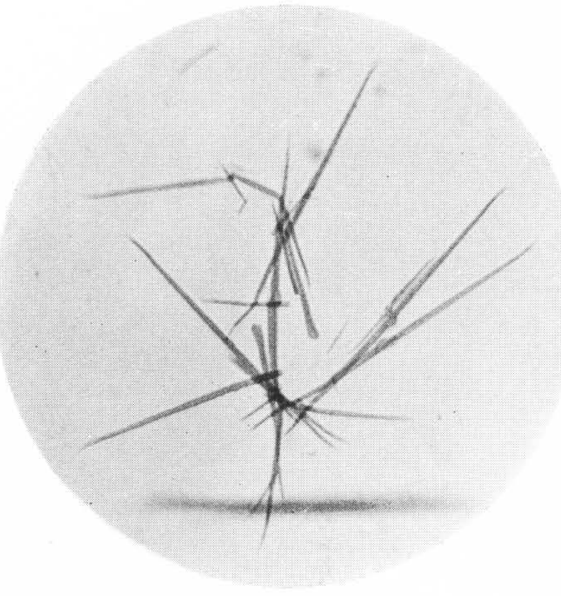

3

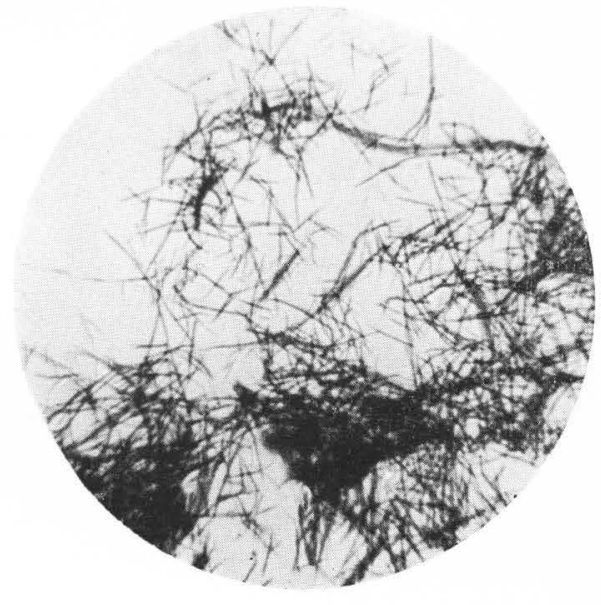

PLATE XXX

2

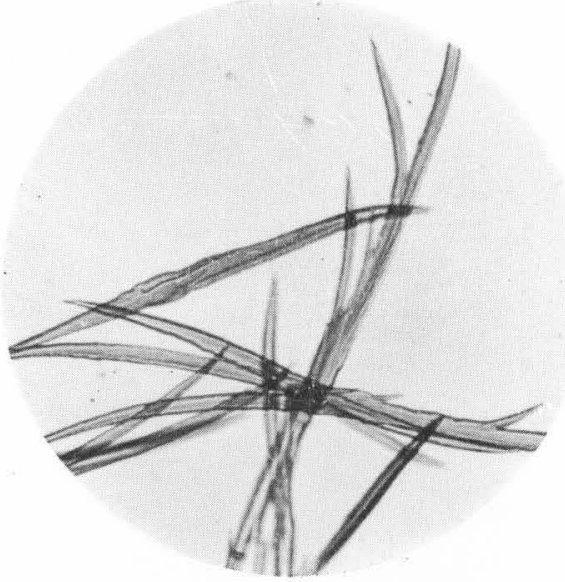

4

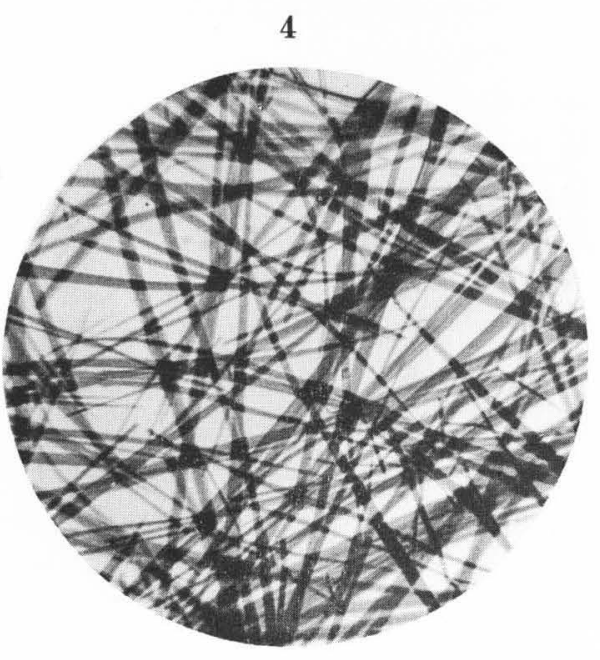

5

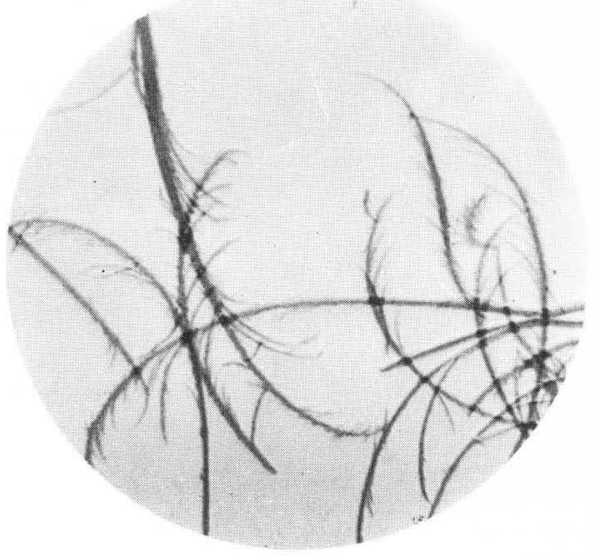

K. Nishibori: Studies on the Pigments of Marine Animals, VII. 